\title{
FREQUENCY OF OSTEOPOROSIS AND OSTEOPENIA AND ITS ASSOCIATED FACTORS AMONG GENERAL POPULATION IN FAISALABAD.
}

\footnotetext{
1. $\mathrm{MBBS}, \mathrm{MMCH}$ Senior Demonstrator Department of Community Medicine University Medical and Dental College Faisalabad.

2. MBBS, MPH

Demonstrator

Department of Community Medicine University Medical and Dental College Faisalabad.

3. MBBS, MPH (Australia) Assistant Professor Department of Community Medicine University Medical and Dental College Faisalabad.

4. MBBS, MCPS, MPH, MPHR (Australia, CSHS (JHU) Professor Department of Community Medicine University Medical and Dental College Faisalabad.

Correspondence Address: Dr. Sameea Nazir

sameea.nazir@tuf.edu.pk

Article received on: 27/08/2019

Accepted for publication: 25/10/2019
}

\section{Sameea Nazir ${ }^{1}$, Uzma Sagheer ${ }^{2}$, Sumera Riaz ${ }^{3}$, Zahid Masood Khan ${ }^{4}$}

ABSTRACT: Osteoporosis means "porous bone". This condition occurs when body lose minerals like calcium more than body can replace it and this leads to thinning of bone mass and increase fragility of bones. This disease is a silent public health issue because of its increasing morbidities, mortalities and disabilities. Objectives: 1 . To determine the frequency of osteoporosis and osteopenia. 2. To find out risk factors associated with osteoporosis and osteopenia. Study Design: This was a Cross Sectional study. Setting: In a private sector Medical College of Faisalabad. Period: From $1^{\text {st }}$ June 2018 to $1^{\text {st }}$ December 2018. Material \& Methods: After approval from ethical review committee, this study was conducted through the BMD screening camps held in a private sector Medical College of Faisalabad. It was a cross-sectional study. Data was collected through well-structured close-ended questionnaire. Convenient sampling was done. Calcaneal quantitative ultrasound machine was used to assess bone mineral density of the participants through their right heel. BMD values in the form of T-score were converted by machine. Results: Out of 116 participants 20 (17\%) were male and $96(83 \%)$ were female. Factors that were statistically $(p \leq 0.05)$ associated with osteoporosis and osteopenia were female gender and inadequate physical activity. More than $50 \%$ of the women had either osteoporosis or osteopenia and doing regular physical activity were mainly significant determinants. Exposure to sunlight was not associated with the low BMD or osteoporosis $(p>0.05)$. Conclusion: It is concluded from this study that important modifiable risk factors like increase in calcium and vitamin $D$ intake and life style modification can improve bone health. Health education and awareness programs with special reference to balanced diet should be held to educate general population.

Key words: $\quad$ BMD, Osteoporosis, Osteopenia.

Article Citation: Nazir S, Sagheer U, Riaz S, Khan ZM. Frequency of Osteoporosis and Osteopenia and its associated factors among general population in Faisalabad. Professional Med J 2019; 26(12):2216-2221. DOI: 10.29309/TPMJ/2019.26.12.4073

\section{INTRODUCTION}

Osteoporosis is a disease characterized by structural destruction of bone mass and tissue which results in increase in bone fragility and tendency to fracture. Nearly nine million fractures occur annually worldwide due to osteoporosis. ${ }^{1}$ Osteoporosis is a global health issue, since there are around 200 million people with this disease in the World. ${ }^{2}$

Osteoporosis, due to its worldwide prevalence, considered to be a serious public health issue. It is calculated that at present time over 200 million people worldwide are suffering from this disease. Worldwide about 1.6 million hip fractures occur each year, this incidence is about to increase to 6.3 million by 2050 outside Europe and the united states. ${ }^{3}$ In USA and Europe approximately $30 \%$ of post-menopausal women suffer from osteoporosis. Worldwide, one-third of women and one fifth of men are estimated to affect from osteoporosis and bone fracture. A preliminary investigation in Hong Kong revealed that 35\% of adult office workers were suffering with either osteoporosis or osteopenia. ${ }^{4}$ In China prevalence of osteoporosis among one-third of people of age group 50 years and above has increased over the past 12 years. Risk of osteoporosis and osteopenia increases with increasing age especially in females than males. ${ }^{5}$ Due to rapidly increasing population and rapidly ageing across, osteoporosis is a growing health concern across 
this region. In most of Asian countries during the past 30 years hip fracture rates have increased by 2- to 3 times. $^{6}$

Osteoporosis has become a leading health problem in our country as there is no clear or sparse epidemiological data on the prevalence of osteoporosis and number of (osteoporotic) hip fractures per year. A cross-sectional study conducted in primary health care settings in Karachi showed the prevalence of osteoporosis was $30.7 \%$ and the prevalence of osteopenia was $44.5 \%$ and it was associated with less daily physical activity, lack or low calcium intake, insufficient sun exposure, intake of tobacco. Overweight and non-communicable diseases like diabetes and depression has strong association with low bone mineral density. ${ }^{7}$

Low bone mass is a serious health problem and its less severe form is osteopenia which is a precursor to osteoporosis. Both osteoporosis and osteopenia has several factors, some are modifiable and some are non-modifiable. Nonmodifiable risk factors of both osteoporosis and osteopenia include old age, female gender, thin/small built, Asian origin, and positive family history of osteoporosis. Modifiable factors include sedentary lifestyle, calcium and vitamin D deficiency, smoking, excessive alcohol and caffeine intake, certain drugs if prolonged used, malabsorbtion conditions. ${ }^{7}$

Due to lack of awareness, illiteracy, inaccessibility and unavailability of health care facilities most of our country's population residing in rural areas does not pay attention to this silent killer disease. Therefore, osteoporosis remains underdiagnosed and untreated. ${ }^{8}$ According to a study, millions of population of Pakistan is suffering from osteopenia and osteoporosis. ${ }^{9}$ Therefore present study is carried out to highlight prevalence of this silent public health problem and to probe its associated risk factors.

\section{MATERIAL AND METHOD}

This was a cross sectional study conducted from $1^{\text {st }}$ June 2018 to $1^{\text {st }}$ December 2018. Convenient sampling technique was used.

\section{Setting}

After approval from ethical review committee this study was conducted in a private sector Medical College of Faisalabad. Screening camps were arranged using the BMD machine. By using convenient sampling technique, 116 participants were included in the study. Written consent was taken, and confidentiality was assured. Data was collected through structured questionnaire based on risk factors of osteoporosis. Bone mineral density was done on calcaneus using the BMD machine (Osteosys 3000) in the form of T-score. Data was analyzed through SPSS version 17. P $<0.05$ was considered statistically significant. Participants based on the WHO criteria for $\mathrm{T}$ score were divided into three groups: normal, osteopenic, and osteoporotic.

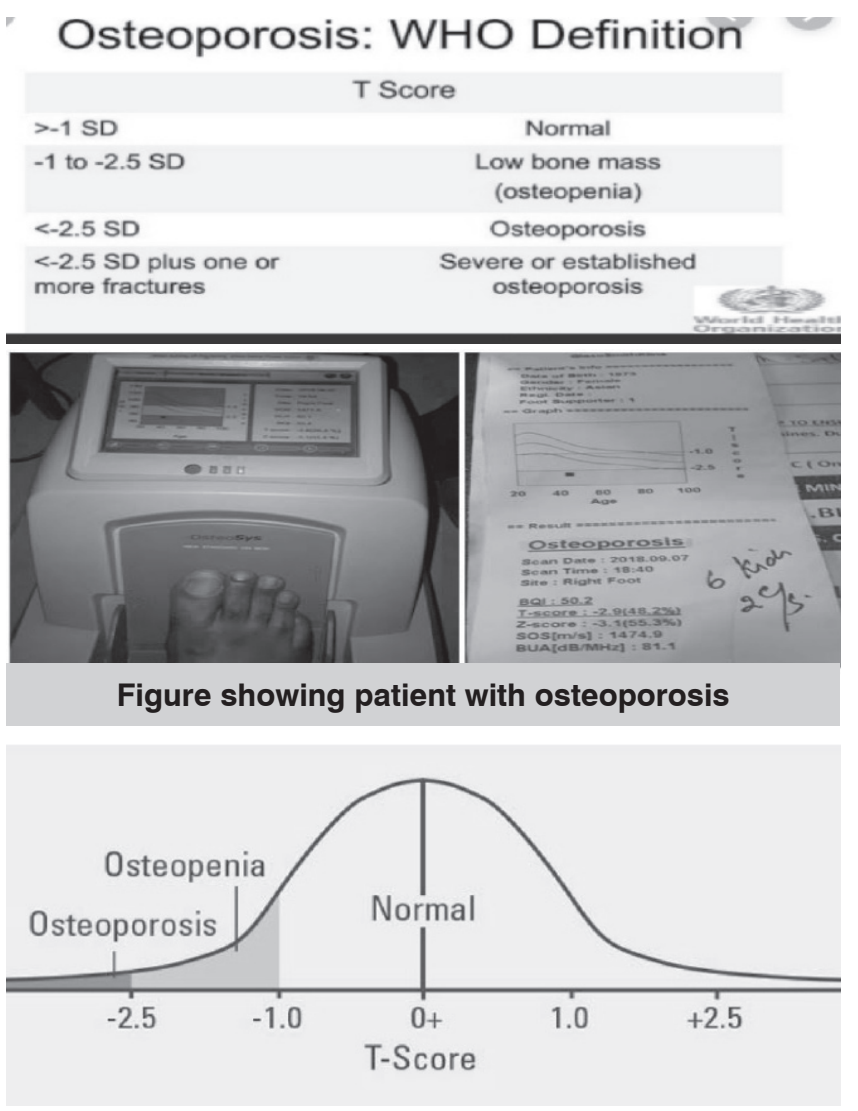

\section{RESULTS}

Out of 116 participants 20 (17\%) were male and $96(83 \%)$ were female. Out of 20 male participants, $12(60 \%)$ were osteopenic, $7(35 \%)$ were normal and $1(5 \%)$ was osteoporotic. And out of 96 females, 65 females (67.7\%) were osteopenic, $17(17.7 \%)$ had osteoporosis and $14(14.5 \%)$ were 
normal as shown in Figure-1. According to age 65 were of age $<30$ years, 37 were of age between $30-45$ years and 14 were of age $>45$ years. Our study results showed that $66.4 \%$ of participants were osteopenic, $15.5 \%$ were osteoporotic and $18 \%$ were normal. With reference to daily exercise among 29 participants having regular physical activity 16 were having osteopenia, 9 normal and 4 osteoporotic. Furthermore, among 87 participants who didn't have regular physical activity 61 were osteopenic, 14 were osteoporotic and 12 were normal as shown in Figure-2. Among 67.2\% who exposed to sunlight $43 \%$ were osteopenic and $11.2 \%$ were osteoporotic. ( $p>0.05)$ and among $32.8 \%$ who had not exposed to sunlight $23.2 \%$ were osteopenic and $4.3 \%$ were osteoporotic as shown in fig 3 . Variables showing correlation with osteoporosis and osteopenia with their $p$ values are shown in Table-l.

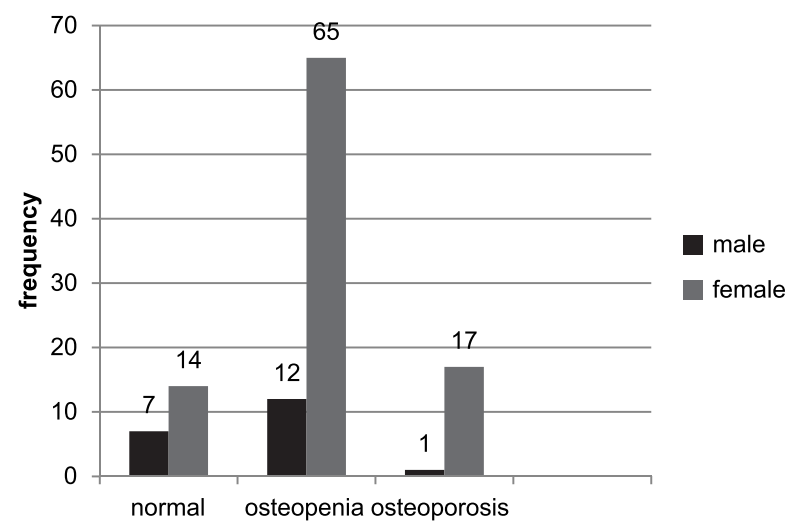

Figure-1. Frequencies of male and female having osteoporosis and osteopenia

Out of 116 participants 20 (17\%) were male and $96(83 \%)$ were female. Out of 20 male participants, $12(60 \%)$ were osteopenic, $7(35 \%)$ were normal and $1(5 \%)$ was osteoporotic. Moreover, out of 96 females, 65 females (67.7\%) were osteopenic, $17(17.7 \%)$ had osteoporosis and $14(14.5 \%)$ were normal.

\begin{tabular}{|c|c|c|c|c|c|}
\hline Characteristics & Number & Normal & Osteopenia & Osteoporosis & P-Value \\
\hline \multirow{2}{*}{ Gender } & Male $(n=20)$ & 7 & 12 & 1 & \multirow{2}{*}{$=0.05$} \\
\hline & Female $(n=96)$ & 14 & 65 & 17 & \\
\hline Exercise daily & Yes $(n=29)$ & 9 & 16 & 4 & $<0.05$ \\
\hline \multirow{2}{*}{ Sun exposure } & Yes $(n=78)$ & 15 & 50 & 13 & \multirow{2}{*}{$>0.05$} \\
\hline & $\mathrm{No}(\mathrm{n}=38)$ & 6 & 27 & 5 & \\
\hline
\end{tabular}

Table-I. Comparison of variables/characteristics among normal, osteopenic and osteoporotic Individuals

Figure-2 showed that among 29 participants having regular physical activity 16 participants were osteopenic, 9 were normal and 4 were osteoporotic and among 87 participants who didn't have regular physical activity 61 were osteopenic, 14 were osteoporotic and 12 were normal.

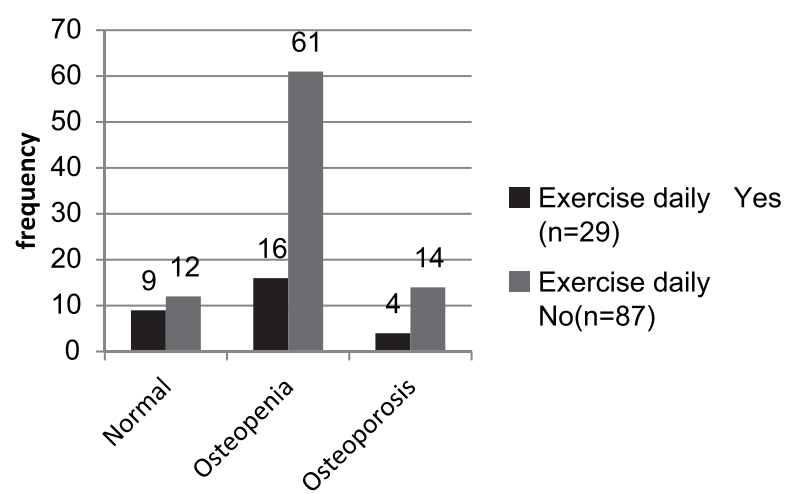

Figure-2. Association between daily exercise and osteoporosis and osteopenia

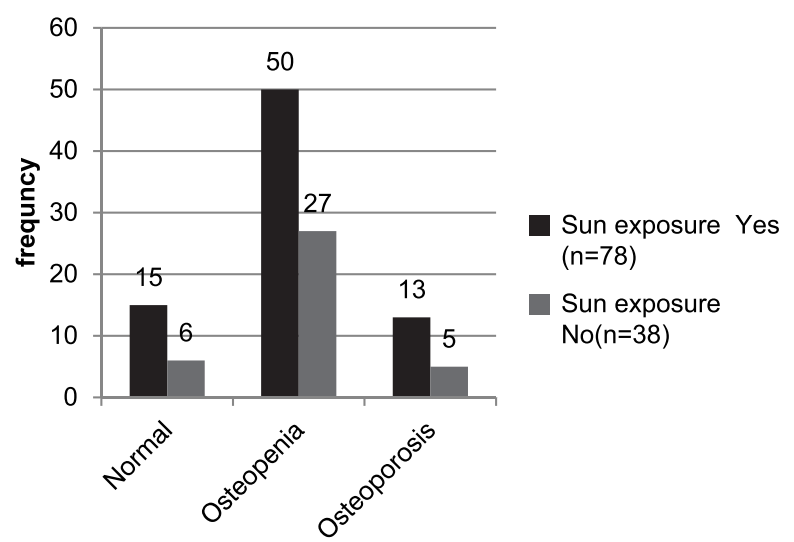

Figure-3. Association between sunlight exposure with osteoporosis and osteopenia

Figure-3 showed that among 78 participants, who exposed to sunlight, 15 were normal, 50 were osteopenic and 13 were osteoporotic and among 38, who had not exposed to sunlight, 6 were normal, 27 were osteopenic and 6 were osteoporotic. 


\section{DISCUSSION}

Osteoporosis is a common metabolic and skeletal disorder and serious public health problem on which little attention has paid in many developing countries including Pakistan and there are several reasons for this negligence. One reason is the acceptance that osteoporosis is an unavoidable consequence of ageing and false belief that osteoporosis is a disease of developed countries. ${ }^{8}$

In our study out of 116 participants 20 (17\%) were male and 96 (83\%) were female. out of 20 male participants, 12 were osteopenic, 7 were normal and one was osteoporotic. Out of 96 females, 65 females were osteopenic, 17 had osteoporosis and 14 were normal $(p=0.05)$. This is comparable to a study conducted in Nigeria which showed that point prevalence of osteoporosis (56.9\%) was high among females than males (males $=43.7 \%$ and females $=65.8 \%) .{ }^{10}$ Another similar study conducted in Karachi also showed that factors that were statistically significantly, associated with low bone mineral density was female gender for osteoporosis. ${ }^{7}$ In another study conducted at Oman revealed that osteoporosis is strongly associated with female gender. ${ }^{11}$

Our study showed that having exercise daily, among 29 participants, 16 were having osteopenia ,9 normal and 4 were osteoporotic and among 87 participants who didn't have regular physical activity 61 were osteopenic, 14 were osteoporotic and 12 were normal. Another study which is comparable to our results showed that only $9 \%$ participants who were involved in regular physical activity were not associated with low bone mineral density, and those who didn't work-out daily or having sedentary lifestyle and behavior was significantly associated with low bone mineral density. ${ }^{7}$ According to WHO (2011) worldwide, physical inactivity has been ranked as the fourth leading risk factor for causing an estimated 3.2 million deaths globally. ${ }^{7}$ Similarly, study conducted in Nigeria also showed that non participation in sporting activities at younger ages and lack of interest in occupational activities were significantly associated with the prevalence of osteoporosis. ${ }^{10}$ Our result is compatible with another study conducted during 2015-2016 at
University Clinical Center of the Republic of Bosnia and Herzegovina depicting that physical activity was a key to good bone health $(p=0.036) .{ }^{12}$

We found that $67.2 \%$ who exposed to sunlight, $43 \%$ were osteopenic and $11.2 \%$ were osteoporotic and among $32.8 \%$ who had not exposed to sunlight $23.2 \%$ were osteopenic and $4.3 \%$ were osteoporotic due to extremes of weather in this part of country. However, result was statistically insignificant $(p>0.05)$. This dichotomy can be attributed to the fact that in countries like Pakistan due to social, cultural and religious grounds females in particular don't get enough sunlight to be effective. Furthermore, females in particular are concerned about their skin with the fear of sunburns, wrinkling so in general the face is not exposed to time period desirable for optimal levels of vitamin $D$ from the exposure to sunlight. This is endorsed by a study concluding that chronic excessive sun exposure also damages the elastic structure of the skin, increasing the risk of wrinkling. ${ }^{13}$ In general even males receive vitamin $D$ from sun in inadequate amount as exposed skin is less than 10 percent. It has been shown in a study that rural populations, who are agricultural laborers exposed to sunlight for more than 4 hours with at least $35 \%$ of their body surface area exposed to sunlight, also have vitamin D deficiency. Moreover, unlike West where population has fair skin color in this part of world skin color is not fair enough and melanin gives it a darker appearance this pigment could be one reason of poor absorption of vitamin $D$ from sun exposure. ${ }^{14}$ Further, it was difficult for our participants to quantify duration and exact timings of exposure to sunlight. In another study it was narrated that dark complexion, poor sunlight exposure as most of the study population had minimal exposure as they were completely covering their bodies with only face, forearm and feet exposed to sunlight. ${ }^{15}$

\section{LIMITATIONS}

Firstly, our study was a cross-sectional study so that it might have over or under estimated frequency of osteoporosis and osteopenia and its associated risk factors especially quantification of exposure to sun light. Secondly we have sampling 
frame which was limited to only one city and its specific areas so that we cannot apply these results on whole Pakistani population.

\section{CONCLUSION}

It is concluded from this study that important modifiable risk factors like increase in calcium and vitamin $\mathrm{D}$ intake and life style modification can improve bone health. In order to find out prevalence of osteopenia and osteoporosis and their associated risk factors among Pakistani population, more researches are required. Awareness programs are required to be held among population to address this serious health issue. More focused approach is required on preventive measures highlighting the importance of these factors on bone health from the earliest period.

Copyright@ 25 Oct, 2019.

\section{REFERENCES}

1. Johnell $O$, Kanis JA. An estimate of the worldwide prevalenceand disabilityassociated with osteoporotic fractures. Osteoporosis Int.2016; 17(12):1726-33.

2. Neelam K, Divya V, Rajinder K.Jalali, Sujeet Jha. Prevalence of osteoporosis and osteopenia in an apparently healthy Indian population - a crosssectional retrospective study osteoporosis and sarcopenia. 2018; 4(2)53-60.

3. Burge R, Dawson-Hughes B, Solomon DH, Wong JB, King $A$, Tosteson $A$. Incidence and economic burden of osteoporosis-related fractures in the United States, 2005-2025. J Bone Miner Res. 2007; 22:465-75.

4. Cathy L,Simon L, Alan T, Bernadette N,et al. Preliminary investigation on prevalence of osteoporosis and osteopenia: Should we tune our focus on healthy adults? Japan Journal of Nursing Science. 2015; 12, 232-248.

5. Chen P, Li Z, Hu Y. Prevalence of osteoporosis in China: A meta-analysis and systematic review BMC Public Health. 2016; 16: 1039.
6. Mithal A, Kaur P, Osteoporosis in Asia: A call to action. Current Osteoporosis Reports. 2012; 10(4):245-7.

7. Haris S, Jahan F, Afreen A, Ahmed H, Ahmed Z. To determine the risk factors and prevalence of osteoporosis among adult Pakistani population residing in Karachi using quantitative ultrasound technique. J Community Med Health Educ.2014;4(4):299

8. Habib S, Iqbal R, Shahid M, Habib A. Growing prevalence of osteoporosis in Pakistan: Call for action. J Pak Med Assoc. 2015 Feb 1;65(2):230-1.

9. Masood Z, Shahzad S, Saqib A, Ashraf K. Osteopenia and osteoporosis frequency among females. Professional Med J. 2014; 21(3): 477-483.

10. Alongea TO, Adebusoyeb LA, Ogunbodec AM, Olowookereb OO, Ladipoc MMA, Balogund WO, Adesomojue VO. Factors associated with osteoporosis among older patients at the Geriatric Centre in Nigeria: A cross-sectional study. South African Family Practice 2017; 59(3):87-93.

11. Jahan F. Osteoporosis: A Silent Killer. Jahan, J Women's Health Care 2015; 4:5.

12. Bijelic R, Milicevic S, Balaban J. Risk Factors for osteoporosis in postmenopausal women Med Arch. 2017;71(1): 25-28.

13. Contet-Audonneau JL, Jeanmaire C, Pauly G. A histological study of human wrinkle structures: Comparison between sun-exposed areas of the face, with or without wrinkles, and sun-protected areas. $\mathrm{Br}$ J Dermatol 1999; 140:1038-47.

14. Clemens TL, Henderson SL, Adams JS, Holick MF. Increased skin pigment reduces the capacity of skin to synthesize vitamin D3. Lancet 1982; 1:74-6.

15. Tariq S, Tariq S, Pervez K. Interplay of vitamin D, vitamin $\mathrm{B}_{12}$, Homocysteine and bone mineral density in postmenopausal females. Health Care for Women International. 2018; 39(12): 1340-1349. 


\begin{tabular}{|c|c|c|c|}
\hline \multicolumn{4}{|c|}{ AUTHORSHIP AND CONTRIBUTION DECLARATION } \\
\hline Sr. \# & Author(s) Full Name & Contribution to the paper & Author(s) Signature \\
\hline 1 & Sameea Nazir & $\begin{array}{l}\text { Data collection, Organizing } \\
\text { draft, Manuscript writing. }\end{array}$ & \\
\hline 2 & Uzma Sagheer & $\begin{array}{l}\text { Data collection, Data entry and } \\
\text { analysis. }\end{array}$ & \\
\hline 3 & Sumera Riaz & Proof reading. & \\
\hline 4 & Zahid Masood Khan & Data review, Proof reading. & \\
\hline
\end{tabular}

